\title{
A Family Showing Transmission of a Translocation $\mathrm{t}(3 \text { porq }-; \mathrm{Cq}+)^{*}$
}

\author{
JOHN MCHUGH, $\uparrow$ TREVOR WRIGHT, and PATRICIA COOKE
}

\section{From Whittington Hall Hospital, Chesterfield, the United Sheffield Hospitals, and the Centre for Human Genetics, United Sheffield Hospitals}

Clarke et al in 1964 reported a translocation complex of the form $46, \mathrm{t}(3 \mathrm{porq}-; \mathrm{Cq}+$ ) segregating in the family of a mentally retarded girl. This paper reports a family in which the chromosome morphology was apparently identical but where different clinical features were observed.

\section{The Family (Fig. 1)}

The patient was born on 28 May 1950 when the mother (I.3) was 28 and the father (I.2) was 29 years old. She was the second child. The first child (II.1) was stillborn and was reported to have had a cleft palate.
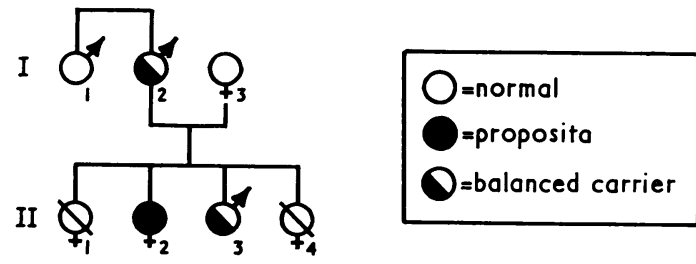

FIG. 1. Family pedigree.

The third child (II.3) was phenotypically normal and the fourth (II.4) died at the age of one month with congenital heart disease. The father's brother (I.1) was unmarried. We are unable to obtain samples from this brother or the grandparents.

\section{Case Reports}

Studies. The patient was born at home and seen by a surgeon at the age of 1 month because of the presence of a bilateral hare lip and complete cleft of both hard and soft palates. Five operations for repair of these defects necessitated frequent hospitalization. She was mentally and physically retarded and did not sit up until 1 year old

\footnotetext{
Received 30 November 1970.

* Reprint requests: United Sheffield Hospitals, Centre for Human Genetics, 117 Manchester Road, Sheffield.

† Present address: Smiths' Falls Hospital, Ontario, Canada.
}

or walk until 4 years. At the age of 7 she was sent to a junior training centre. She was transferred to an adult centre at 16 years but was found to be unsuitable and sent to a special care unit. At the age of 18 she was admitted to a hospital for the mentally handicapped.

On admission the proposita (Fig. 2) was $1.5 \mathrm{~m}$ tall, weighed $43.5 \mathrm{~kg}$, and had a head circumference of $50 \mathrm{~cm}$. Her hair was black and projected down over the forehead in the centre. She had brown eyes with a convergent squint but no specific abnormalities of iris or cornea. The nasal bridge was broad and flattened and she had epicanthus, more prominent on the right side. There was a defective nasal septum and a repaired cleft lip and palate. The lower lip was grossly everted and the teeth were irregular. The ears were fairly mature in their development.

Her breasts were underdeveloped; the right breast was somewhat larger than the left. They were set very low and in a lateral position. Pubic and axillary hair was scanty. The external genitalia were normal and she had menstruated regularly from the age of 11 years. The cardiovascular system, chest $x$-ray, abdomen, and CNS system were normal. She had a flexion defect of the fingers with angulation of the proximal interphalangeal joints especially in the 2nd, 3rd, and 4th digits. There was some hyperexstensibility of the metacarpophalangeal joints, and some webbing between the fingers which were long and tapering. There was some reduction of tone in the upper limbs and though the reflexes were present and equal on both sides, the responses seemed sluggish. In contrast, the tone of the lower limbs seemed normal with brisk equal reflexes and flexor plantar responses.

Dermatoglyphs. The total ridge count (for the fingers of both hands) was 115 , approximating to the population mean for females $(127 \pm 53)$. In the right hand the thumb and 1st finger showed ulnar loops with whorls on the remaining fingers. In the left hand the thumb had an ulnar loop with whorls on the remaining fingers. The flexion creases were normal with no Sydney or Simian lines. The distal $c$ triradius was absent in both hands. The $e$ and $f$ triradii on the left and right hallucal areas were associated with well-marked normal ridge patterns. 


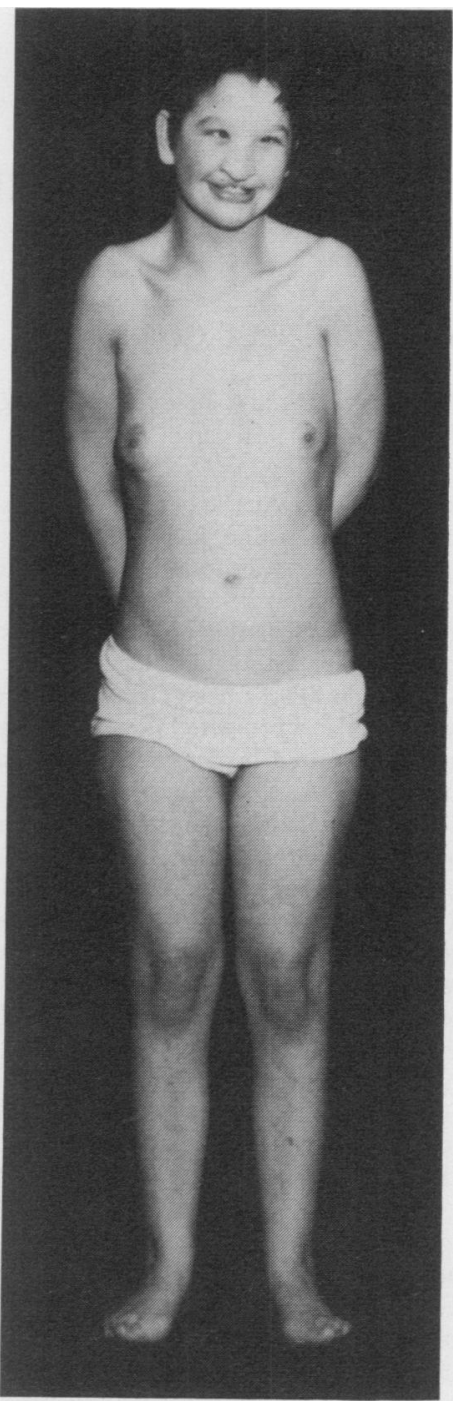

(a)

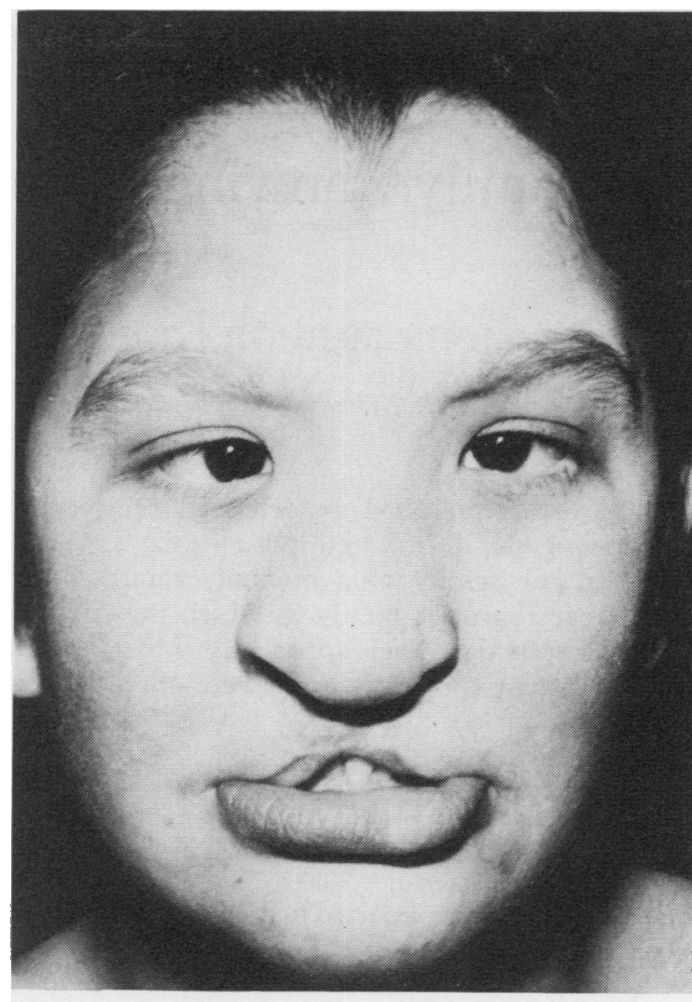

(b)

FIG. 2a and 2b. The proposita.

Psychometric assessment. She had practically no executive speech although she was able to communicate with the aid of gesticulation. She was able to understand simple instructions although generally language development was too restricted for assessment by the Illinois Test. It was difficult to assess her IQ on the Stanford-Binet scale because of her verbal limitations but her aggregate mental age was estimated to be in the region of $2+$ years. Her personal/social development seemed to be slightly in advance of this level as measured by the Vineland Social Maturity Scale.

TABLE

BLOOD GROUP DATA

\begin{tabular}{|c|c|c|c|c|c|c|c|c|c|}
\hline I. 2 & $\stackrel{0}{\mathrm{Gml}-}$ & $\begin{array}{l}\text { MMs } \\
2-\end{array}$ & $\begin{array}{l}P_{1} \\
4+5+\end{array}$ & $\begin{array}{l}\mathrm{CDe} / \mathrm{cde} \\
\text { Invl - }\end{array}$ & $\mathbf{L u}^{\mathbf{a}-}$ & $\mathrm{K}^{\mathrm{a}-}$ & $L e^{a-b+}$ & $F y^{a-}$ & $J^{a} \mathbf{a}+b+$ \\
\hline I. 3 & $\begin{array}{l}A_{1} \\
\mathbf{G m l}-\end{array}$ & $\begin{array}{l}\text { MNs } \\
2-\end{array}$ & $\begin{array}{l}P_{1} \\
4+5+\end{array}$ & $\begin{array}{l}\mathrm{CDe} / \mathrm{cde} \\
\text { Invl - }\end{array}$ & $\mathbf{L u}^{\mathbf{a}-}$ & $\mathrm{K}^{\mathrm{a}-}$ & $\mathbf{L e}^{\mathrm{a}-\mathrm{b}-}$ & Fya - & $J k^{a-b+}$ \\
\hline II. 2 & $\stackrel{0}{\mathrm{Gm} l-}$ & $\begin{array}{l}\text { MNs } \\
2-\end{array}$ & $\begin{array}{l}P_{1} \\
4+5+\end{array}$ & $\begin{array}{l}\text { cde/cde } \\
\text { Invl - }\end{array}$ & $\mathrm{Lu}^{\mathrm{a}-}$ & $\mathrm{K}^{\mathbf{a}-}$ & $L e^{a-b+}$ & Fya - & $\mathbf{J k}^{\mathbf{a}+\mathbf{b}+}$ \\
\hline II. 3 & $\stackrel{0}{\mathrm{Gm} \mathbf{m}-}$ & $\begin{array}{l}\text { Mns } \\
2-\end{array}$ & $\begin{array}{l}p_{1} \\
4+5+\end{array}$ & $\begin{array}{l}\text { cde/cde } \\
\text { Invl- }\end{array}$ & $\mathbf{L u}^{\mathbf{a}-}$ & $\mathbf{K}^{\mathbf{a}-}$ & $\mathrm{Le}^{\mathrm{a}-\mathrm{b}+}$ & Fya - & $\mathrm{Jk}^{\mathrm{a}+\mathrm{b}+}$ \\
\hline
\end{tabular}


Investigations. Blood and amino-acid chromatogram were normal. Skull radiology showed the vault bones to be heavy with a small cranial cavity. The pituitary fossa was not well shown but also appeared small. Radiology of the left wrist showed the bone age to be over 17 years of age. The WR, Kahn, and Reiter PCFT were negative. Toxoplasma titre was 1 in 8 . The EEG record was normal, though the tracing contained some artefacts. Blood groups and types were determined and the results are given in the Table; no anomalies were observed.

Chromosome Analysis. This was performed on preparations of peripheral blood taken from the proposita, her sib, her mother, and her father. The father and male sib were both found to be carriers of a balanced translocation complex of the form $46, \mathrm{XY}, \mathrm{t}$ (3porq-;
$\mathrm{Cq}+)$ see Fig. 3. The mother was normal $(46, \mathrm{XX})$ and the propositus had the karyotype $46, \mathrm{XX}, \mathrm{t}(\mathrm{Cq}+)$ pat (Fig. 4). The $\mathrm{C}$ group chromosome involved could not have been an $\mathrm{X}$ since the male sib had inherited the abnormal $C$ from his father.

One leucocyte culture from the proposita was autoradiographically labelled by the addition of $\mathrm{H}^{3}$ thymidine (Sp. Act. $5 \mathrm{mC} / \mathrm{mM}$, final concentration $0.05 \mathrm{c} / \mathrm{ml}) 6$ hours before harvesting. This is now routine procedure for all propositi referred to this centre. As expected, a normal late-labelling $\mathbf{X}$ chromosome was observed. It was possible to distinguish the translocation product from the normal members of the B group by its labelling pattern, notably by the sparseness of labelling on the short arm (Fig. 5). It was not possible to identify the $\mathrm{C}$ group chromosome involved specifically, but from the relative size and labelling pattern, it would seem likely to be one of the smaller members of the group (9-12).

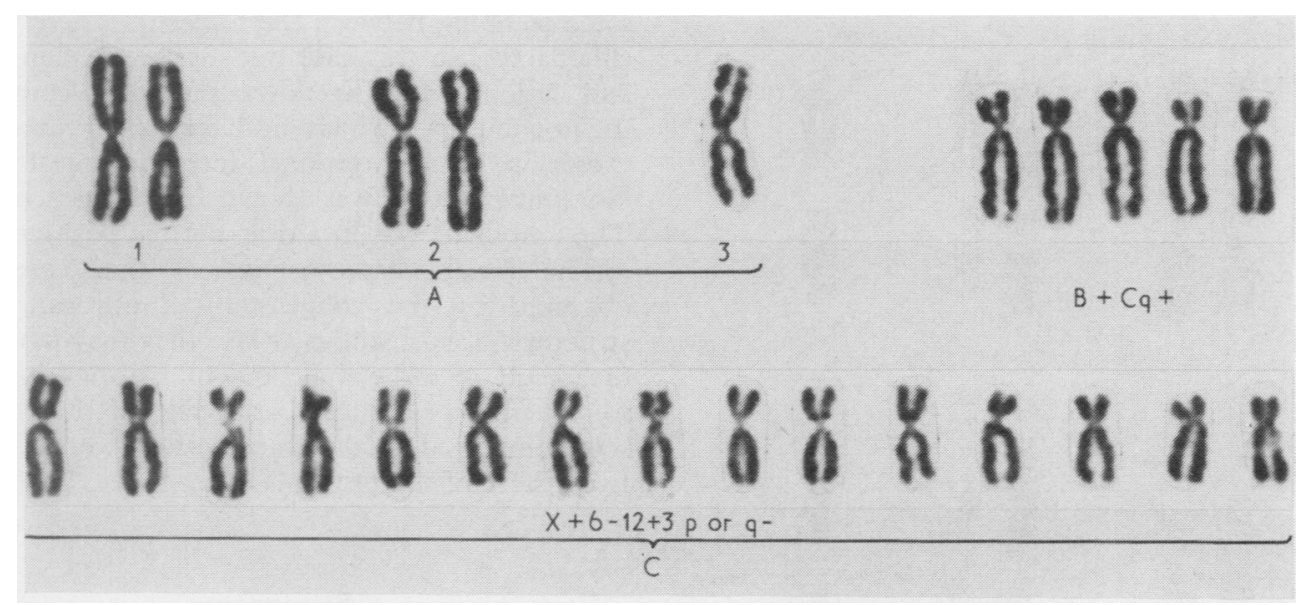

Fig. 3. Partial karyotype of one of the balanced translocation carriers, I.2.

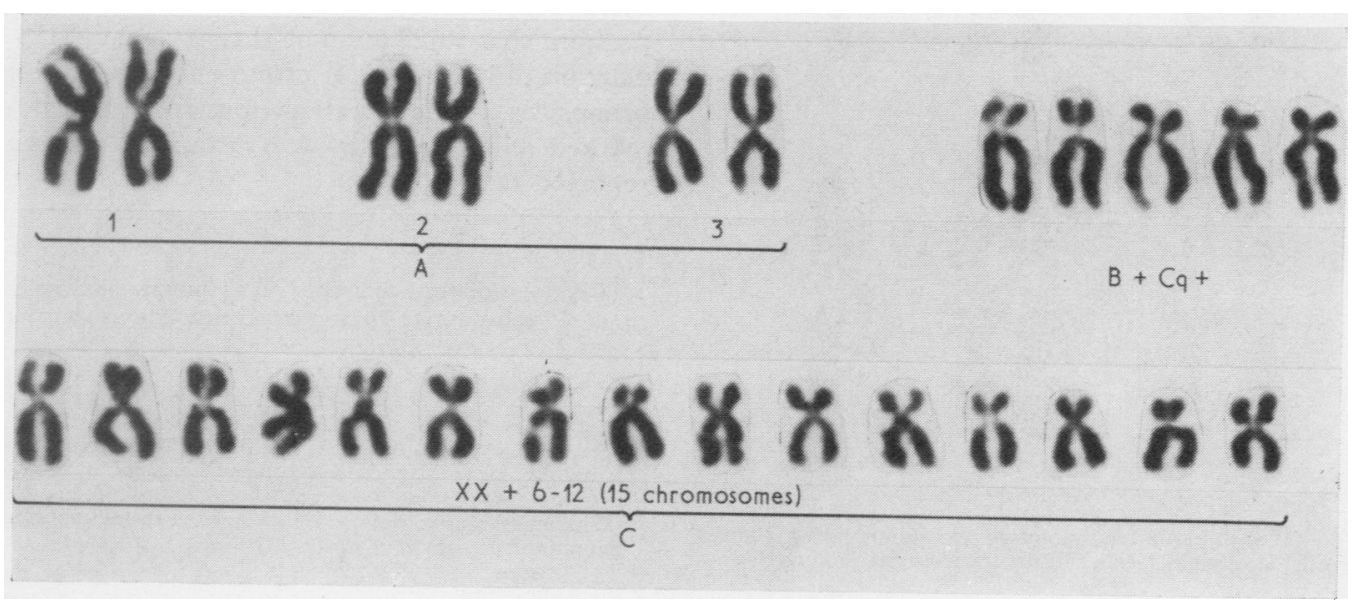

FIG. 4. Partial karyotype of the proposita, II.2. 


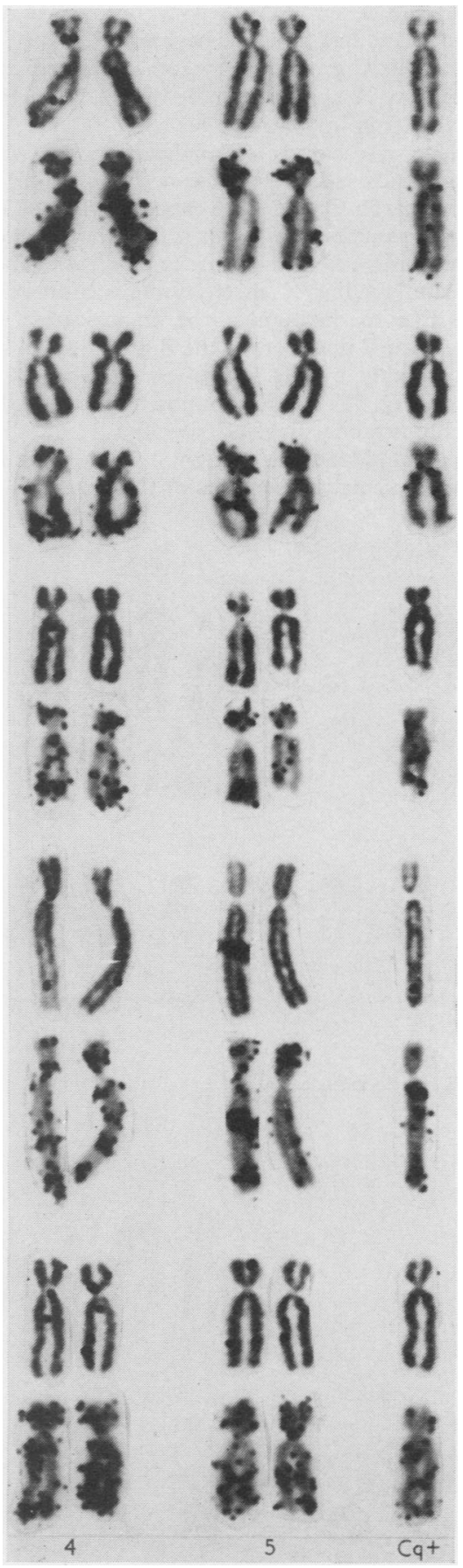

Fig. 5. The $B$ group chromosomes in the proposita showing differential labelling behaviour of the translocation product, $\mathrm{Cq}+$.

\section{Discussion}

Although the karyotypes of the present case and that of Clarke et al (1964) seemed to be identical $\stackrel{\mathbb{P}}{?}$ there were great disparities in the clinical features $\vec{\Rightarrow}$ observed. The differences may be explained most simply by assuming that either a different $C$ group chromosome or the other arm of the 3 was involved, or even a combination of both these factors.

Both patients showed severe mental retardation. In the previous case the proposita was below the क mean height for her age whereas the present case $\overrightarrow{0}$ was above the mean height. Both patients had strabismus but the previous case showed no epi- $\vec{\omega}$ canthus. Clarke's case showed webbing of the neck, which was short and the hands were small and 0 'chubby' with tapered fingers. In the present case 90 the fingers were long and tapered and there was $\vec{i}$ some webbing between the fingers. There was no $\&$ clinodactyly in this case but marked flexion of the 2nd, 3rd, and 4th fingers was present in contrast to the previous case which did have some limitation of $c$ extension of the terminal interphalangeal joints. No simian crease was shown in the present case. The umbilicus was in a near-normal position.

The facial characteristics of this case were obscured by the congenital deformities. These structural abnormalities, while they may have bee? the result of some independent mal-development. were perhaps significant, especially if the chromos somes involved in the translocation were different from those of the previous case.

\section{Summary}

The chromosome anomalies described resemble those reported by Clarke et al (1964) involving presumptive duplication of chromosome No. 3 and deletion of one of the $\mathbf{C}$ group chromosomes in the propositus. The present patient shows quite marked clinical differences from the previously reported case.

We are indebted to Mr. J. A. Cowell, Senior Educational Psychologist, for the psychometric assessment.

\section{REFERENCE}

Clarke, G., Stevenson, A. C., Davies, P., and Williams, C. E. (1964). ర A family apparently showing transmission of a translocation between chromosome 3 and one of the ' $X-6-12$ ' or ' $C$ ' group. (With an appendix: Holt, S. B. A note on the dermal ridge configurations.) Fournal of Medical Genetics, 1, 27-34. 